E3S Web of Conferences 1, 39006 (2013)

DOI: $10.1051 / \mathrm{e} 3$ sconf $/ 20130139006$

(C) Owned by the authors, published by EDP Sciences, 2013

\title{
Mineral Analysis the Infusion of Black Tea Samples by Atomic Absorption Spectrometry
}

\author{
$\underline{\text { N. Lahiji }}{ }^{1}$, F. Tadayon ${ }^{2}$, F. Tamiji ${ }^{3}$ and A. H. Lahiji ${ }^{4}$ \\ ${ }^{1}$ Department of Chemistry, North Tehran Branch, Islamic Azad University, Tehran, Iran, nafisehlahiji@yahoo.com \\ ${ }^{2}$ Department of Chemistry, North Tehran Branch, Islamic Azad University, Tehran, Iran, F_tadayon@iau-tnb.ac.ir \\ ${ }^{3}$ Science and Research Branch, Islamic Azad University, Semnan, Iran, Fateh_tm@yahoo.com \\ ${ }^{4}$ Department of Chemistry, North Tehran Branch, Islamic Azad University, Tehran, Iran, Lahiji_ah@yahoo.com
}

\begin{abstract}
Tea infusion is one of the most popular drinks around the world. Since tea infusion is known to contain several essential nutrients, it is considered a healthy beverage. In this study eight different Iranian brands of tea infusion and eleven brands imported tea infusion samples from another country for $\mathrm{Cu}, \mathrm{Zn}, \mathrm{Mn}$ and $\mathrm{Al}$ were determined by flame atomic absorption spectrometry after wet digestion. The results of analysis showed that the extraction rates of minerals from dry black tea to infusion tea were for $\mathrm{Mn}(19.35 \%), \mathrm{Cu}(22.75 \%), \mathrm{Zn}(54.43 \%)$ and $\mathrm{Al}(61.48 \%)$. The results obtained from this analysis have shown good accuracy.
\end{abstract}

Keywords: Trace elements; Tea infusion; Black tea; Atomic Absorption Spectrometry

\section{Introduction}

Tea, the dried leaves of the Camellia sinensis species of the Theaceae family, is a popular beverage. Various kind of teas including: black, green and oolong, but all come from the same plant. The leaves of the tea plant are used both as a social and medicinal beverage. This beverage has been consumed in many countries for a very long time, and today interest is growing because scientific reports indicate that tea could bring benefits for health (Tadayon and Lahiji, 2011; Shen et al., 2009; Ferrara et al., 2001; Dufresne and Farnworth, 2000). One of the most serious problems facing the world today is contamination of the environment by heavy metals. Heavy metals normally occurring in nature are not harmful, because they are only present in very small amounts. But, their excess may cause disease and be deleterious to health. Thus, determinations heavy metal ion levels in the environment is essential and a requisite for human health and safety (Chuanuwatanakul et al., 2008; Tuzen and Soylak, 2007). Heavy metals are mobile and easily taken up by plants in the environment (Chojnacka et al., 2005). In this study eight different Iranian brands of black tea and twelve brands imported black tea samples from another country (Ceylon, India and South Africa) for copper, Zinc, manganese and aluminum were determined by flame atomic absorption spectrometry after wet digestion. Most of the tea consumed in Iran is grown in these northern regions (Gilan and Mazandaran), and some tea is purchased from other countries. The objective of this pilot study was to determine the percent $(\%)$ extraction of each mineral that would be consumed per cup.

\section{Materials and Methods}

A Varian model Spectra AA-240 (Mulgrava, Victoria, Australia), atomic absorption spectrometer equipped with deuterium lamp background correction was used with hollow cathode lamp(Varian).

Suprapure Merck $\mathrm{HNO}_{3}, \mathrm{HCL}$ and $\mathrm{H}_{2} \mathrm{O}_{2}$ were used in the treatment of tea samples and preparation of standard solutions. All reagents used in the present study were of analytical grade obtained from E. Merck.

Washing procedures: tea sample was washed to remove exogenous contaminants from the surface; therefor each tea sample was washed with deionized water - acetone - deionized water. The first stage of washing tea sample 
was washed with deionized water for $30 \mathrm{~min}$, then acceton for $10 \mathrm{~min}$. and end stage with deionized water for $15 \mathrm{~min}$. The tea sample was oven- dried at $70{ }^{\circ} \mathrm{C}$ for 3 hours.

Mineral analysis of dry tea material : Preliminary studies showed that mixtures of $\mathrm{HNO}_{3}-\mathrm{HCl}-\mathrm{H}_{2} \mathrm{O}_{2}$ are better than either $\mathrm{HClO}_{4}-\mathrm{HCl}$ or $\mathrm{HCl}-\mathrm{H}_{2} \mathrm{O}_{2}$ in terms of complete dissolution in a short time. All tea samples were digested by weighing the sample directly (about $1.5 \mathrm{~g}$ ) into a conical sample tube, and concentrated $\mathrm{HNO}_{3}(65 \%) / \mathrm{HCl}(37 \%) /$ $\mathrm{H}_{2} \mathrm{O}_{2}(35 \%)$ were added. The samples were heated on a hot plate. After digestion, the sample was diluted to final volume with deionized water. Standard solution of each element was prepared in a mixture of $\mathrm{HNO}_{3}, \mathrm{H}_{2} \mathrm{O}_{2}$ and deionized water.

Mineral analysis of infusion liquid: Infusions were prepared by boiling $50 \mathrm{ml}$ of deionized water and pouring the boiling water about $1.5 \mathrm{~g}$ of the dry tea material. The resulting infusion was covered and steeped at $100^{\circ} \mathrm{C}$ for 10 min. After cooling at room temperature, the steeped infusion was separated and evaporated to dryness. The residue was oven- dried at $70{ }^{\circ} \mathrm{C}$ for 3 hours and handled as above for the dry material.

\section{Results and Discussion}

The mean levels of manganese, copper, zinc and aluminum in tea different tea leaves samples and their residues are given in (Tables1 and 2). Manganese and aluminum, ranged in black tea samples at $\mathrm{mg} \mathrm{g}^{-1}$ levels, while copper and zinc were at $\mu \mathrm{g} \mathrm{g}^{-1}$ levels. The percent extraction (Table 3), provided information on the expected amount of each mineral that would be consumed per cup $(50 \mathrm{ml})$.
Manganese is a necessity for the proper function of several enzymes and an essential micro-nutrient for the function of the brain, nervous system, and normal bone growth(Liang et al., 2006). The mean percent extraction manganese content of the black tea samples was $19.35 \%$ ( Table 3).

Copper is an essential element, with both deficiencies and excesses associated with impaired health. Copper deficiency is known to cause various physiologic disorders such as anemia and bone abnormalities (Uauy et al., 1998). The mean percent extraction copper content of the black tea samples was $22.76 \%$ (lowest in Iranian teas, highest imported teas), that showed in Fig 1. Zinc is known to be involved in most metabolic pathways in humans. Zinc deficiency can lead to loss of appetite, growth retardation, skin changes and immunological abnormalities (Reddy et al., 2007). The mean percent extraction achieved for zinc in cultivated teas and imported teas, $49.75 \%$ and $59.10 \%$, respectively.

Al concentrations in all the tea samples analysed are relatively high. The percent $(\%)$ extraction of aluminum in cultivated teas and imported teas were found $55.40 \%$ and $67.57 \%$, respectively. The mean extraction of $\mathrm{Al}$ was $61.48 \%$. Although tea leaves and leaf infusions contain high concentrations of $\mathrm{Al}$, only a small proportion of it is available for absorption in the gastro-intestinal tract (Flaten, and Lund, 1997; Powell et al., 1998). Average extraction rates were best for $\mathrm{Al}(61.48 \%)$, followed by $\mathrm{Zn}(54.43 \%)$, $\mathrm{Cu}(22.75 \%)$ and $\mathrm{Mn}(19.35 \%)$. The mean percentage of $\mathrm{Al}$ in cultivated teas was lower than imported teas, and The mean percentage of $\mathrm{Mn}, \mathrm{Zn}$ and $\mathrm{Cu}$ in imported tea samples were relatively higher than cultivated tea samples.

Tab.1 Mean levels of metals in black tea leaves

\begin{tabular}{|c|c|c|c|c|c|}
\hline \multirow{2}{*}{ Samples } & \multirow{2}{*}{$\begin{array}{c}\text { Number of } \\
\text { samples }\end{array}$} & Mn (mg/g) & $\mathrm{Cu}(\mu \mathrm{g} / \mathrm{g})$ & $\mathrm{Zn}(\boldsymbol{\mu g} / \mathrm{g})$ & $\mathrm{Al}(\mathbf{m g} / \mathrm{g})$ \\
\hline & & Mean $\pm S . D^{a}$ & Mean $\pm S . D^{a}$ & Mean $\pm S . D^{a}$ & $\operatorname{Mean} \pm S . D^{a}$ \\
\hline Imported teas & 11 & $0.469 \pm 0.20$ & $11.54 \pm 0.37$ & $35.70 \pm 0.24$ & $0.373 \pm 0.22$ \\
\hline Cultivated teas & 8 & $0.868 \pm 0.13$ & $16.51 \pm 0.14$ & $38.21 \pm 0.15$ & $0.741 \pm 0.14$ \\
\hline $\operatorname{Mean} \pm S . D^{\mathrm{a}}$ & & $0.669 \pm 0.16$ & $14.03 \pm 0.25$ & $36.96 \pm 0.19$ & $0.557 \pm 0.18$ \\
\hline
\end{tabular}

\footnotetext{
${ }^{\mathrm{a}}$ The quoted SD values are on the basis of range of elemental concentration determined in different tea samples.
} 
Tab.2 Mean levels of metals in black tea residues

\begin{tabular}{|c|c|c|c|c|c|}
\hline \multirow{2}{*}{ Samples } & \multirow{2}{*}{$\begin{array}{c}\text { Number of } \\
\text { samples }\end{array}$} & $\operatorname{Mn}(\mathbf{m g} / \mathbf{g})$ & $\mathrm{Cu}(\mu \mathrm{g} / \mathrm{g})$ & $\mathrm{Zn}(\boldsymbol{\mu g} / \mathrm{g})$ & $\mathrm{Al}(\mathrm{mg} / \mathrm{g})$ \\
\hline & & Mean \pm S.D ${ }^{\mathrm{a}}$ & $\operatorname{Mean} \pm S . D^{a}$ & $\operatorname{Mean} \pm S . D^{a}$ & Mean \pm S.D ${ }^{a}$ \\
\hline Imported teas & 11 & $0.363 \pm 0.31$ & $8.53 \pm 0.26$ & $14.64 \pm 0.27$ & $0.116 \pm 0.64$ \\
\hline Cultivated teas & 8 & $0.731 \pm 0.14$ & $13.43 \pm 0.13$ & $19.2 \pm 0.17$ & $0.330 \pm 0.20$ \\
\hline Mean $\pm S . D^{a}$ & & $0.547 \pm 0.22$ & $10.98 \pm 0.19$ & $16.92 \pm 0.22$ & $0.223 \pm 0.42$ \\
\hline
\end{tabular}

${ }^{a}$ The quoted SD values are on the basis of range of elemental concentration determined in different tea samples.

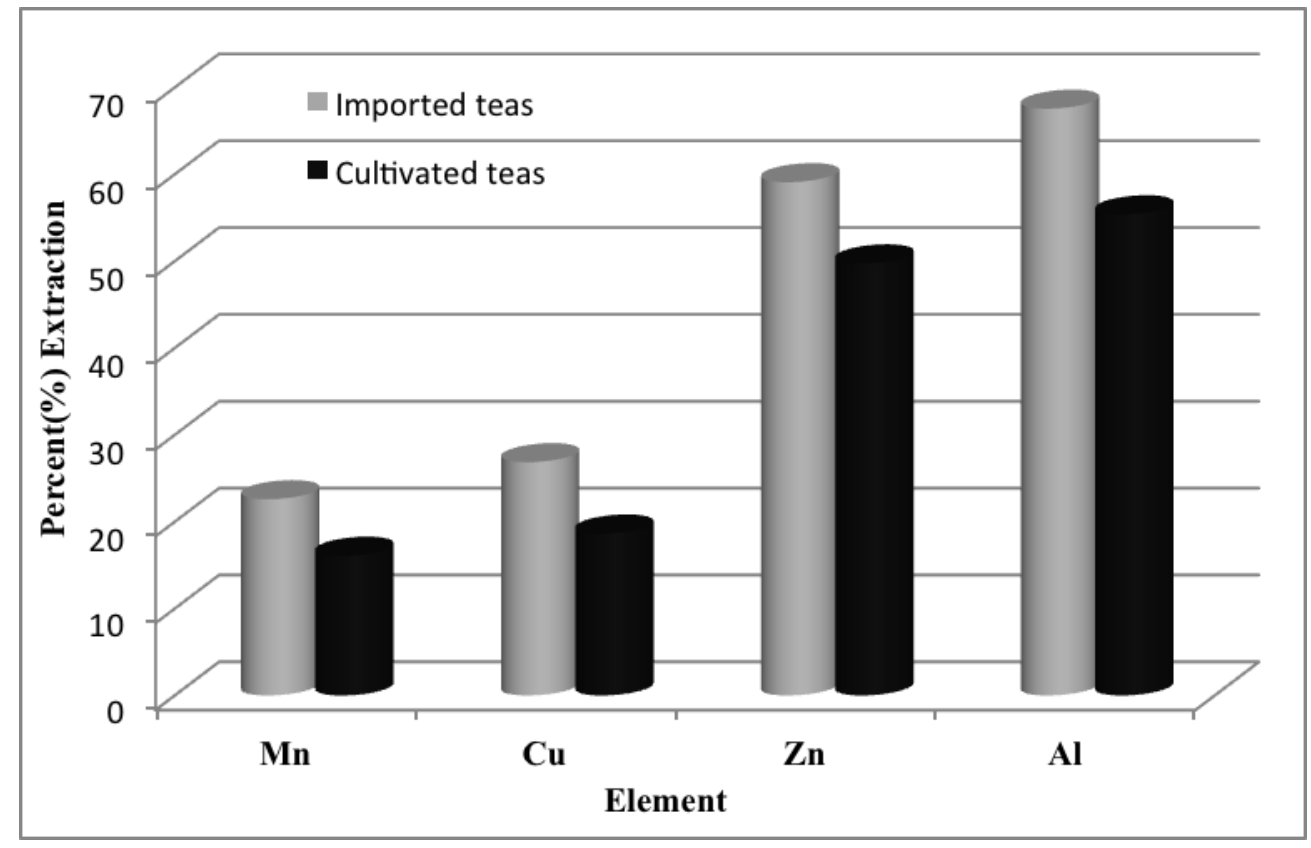

Fig.1 Percent (\%) extraction of studied metals in black tea samples imported and cultivated in Iran

Tab.3 Percent (\%) extraction of minerals from dry tea to infusion $(50 \mathrm{ml})$

\begin{tabular}{|c|c|c|c|c|}
\hline Samples & & $\mathbf{C u}$ & $\mathbf{Z n}$ & Al \\
\hline Imported teas & 22.60 & 26.86 & 59.10 & 67.56 \\
\hline $\begin{array}{l}\text { Cultivated } \\
\text { teas }\end{array}$ & 16.09 & 18.65 & 49.75 & 55.40 \\
\hline Mean & 19.35 & 22.75 & 54.43 & 61.48 \\
\hline
\end{tabular}




\section{Conclusion}

Average extraction rates were best for $\mathrm{Al}$ followed by $\mathrm{Zn}$, $\mathrm{Cu}$ and $\mathrm{Mn}$. The amount of $\mathrm{Al}$ in a cup of the Iranian cultivated black teas was perfected than imported black teas, and no cause to concern. Contributory factors for this difference in the minerals studied in Iranian black tea samples and imported tea samples could be varying metal concentrations in the soils, and the conditions of cultivation and preparation, and these vary between both country of origin and for the type of tea.

\section{Acknowledgements}

The authors wish to thank Ms. Vahideh Mohadjeri for her sincere support in the field.

\section{References}

Chojnacka K, Chojnacki A, Gorecka H, Gorecki H. Bioavailability of heavy metals from polluted soils to plants. The Science of the Total Environment 2005; 337: 175-182.

Chuanuwatanakul S, Dungchai W, Chailapakul O, Motomizu S. Determination of trace heavy Metals by Sequential Injection- anodic Stripping Voltammetry using Bismuth Film Screenprinted Carbon Electrode. Analytical Sciences 2008; 24: 589-594.

Dufresne C, Farnworth E.Tea, Kombucha, and health: a review. Food Research International 2000; 33:409421.
Ferrara L, Montesano D, Senatore A. The distribution of minerals and flavonoids in the tea plant(Camellia sinensis). Il Farmaco 2001; 56: 397-401.

Flaten AK, Lund W. Speciation of aluminium in tea infusions studied by size exclusion chromatography with detection by postcolumn reaction. The Science of the Total Environment 1997; 207: 21-28.

Liang P, Sang H, Sun Z. Cloud point extraction and graphite furnace atomic absorption spectrometry determination of manganese(II) and iron(III) in water samples. J Colloid and Interface Science 2006; 304: 486-490.

Powell JJ, Burden TJ, Thompson RPH. In vitro mineral availability from digested tea: A rich dietary source of manganese. Analyst 1998; 123: 1721-1724.

Reddy KJ, Kumar JR, Ramachandraiah C, Thriveni T, Reddy A. Spectrophoto-metric determination of zinc in foods using N-ethyl-3-carbazolecarboxaldehyde3-thiosemicarbazone: evaluation of a new analytical reagent. Food Chemistry 2007; 101: 585-591.

Shen Chwan-Li, Yeh James K, Cao Jay J, Wang JiaSheng. Green tea and bone metabolism. Nutrition Research 2009; 29: 437-456.

Tadayon F, Lahiji N. Availability of essential and nonessential elements in tea samples produced in Iran. International Journal of Academic Research 2011; 3: 1071-1075.

Tuzen M, Soylak M. Evaluation of trace element contents in canned foods marketed from Turkey. Food Chemistry 2007; 102: 1089-1095.

Uauy R, Olivares M, Gonzalez M. Essentiality of copper in humans. American J Clin Nutr 1998; 67(5 Suppl.): 952S-959S. 